\title{
Genetic investigation of cAMP-dependent protein kinase function in Drosophila development
}

\author{
Mary Ellen Lane and Daniel Kalderon \\ Department of Biological Sciences, Columbia University, New York, New York 10027 USA
}

The cAMP-dependent protein kinase (PKA) has been shown to mediate the vast majority of cellular responses to the intracellular second messenger, cAMP, in eukaryotes. To study the role of cAMP signal transduction in Drosophila development, we have isolated and molecularly characterized mutations of varying severity in the Drosophila PKA gene, DC0. Biochemical measurements indicate that DCO is either the sole or the major PKA catalytic subunit gene in Drosophila. Adult females heterozygous for a strong and a weak DC0 allele fail to lay eggs and show a striking and novel defect in oogenesis that includes the formation of egg chambers containing multinucleate nurse cells. Females heterozygous for two weak DC0 alleles are fertile but produce offspring showing a variety of defects in embryogenesis, including preblastoderm arrest and alterations in cuticular patterning. Animals zygotically null for DCO die as morphologically normal first-instar larvae, implying that maternally encoded protein, which perdures for at least $\mathbf{1 2} \mathbf{~ h r}$, suffices for embryogenesis. Animals hemizygous for weak DC0 alleles survive for several days as larvae but grow slowly. Mitotic recombination experiments in the adult eye indicate that the DCO gene is not required autonomously either for cell viability or normal growth rates. These results argue that cAMP-mediated signal transduction is essential at a variety of stages during the development of a metazoan.

[Key Words: Drosophila, development; oogenesis; cAMP; signal transduction; protein kinase]

Received Janaury 12, 1993; revised version accepted April 29, 1993.

Intercellular communication has been shown to be important to the correct development of many eukaryotes, including Drosophila. An understanding of the molecular pathways underlying these cellular interactions will require a study of signal transduction molecules that are responsible for the first stages of converting a message received at the plasma membrane into a response.

A very large number of physiological cellular responses to extracellular signals have been shown to employ the second messenger, cAMP. The rate of cAMP synthesis, catalyzed by adenylyl cyclase, is modulated via a stimulatory (Gs) or inhibitory (Gi) G-protein that itself responds to an activated transmembrane receptor (Gilman 1984; Levitzki 1988). Although intracellular cAMP has been shown to interact directly with ion channels in olfactory cells (Nakamura and Gold 1987; Dhallan et al. 1990), the vast majority of its effects in eukaryotes are mediated by binding to the regulatory subunit of the inactive cAMP-dependent protein kinase (PKA) tetramer (Coffino et al. 1976; Toda et al. 1987). This dissociates monomeric catalytic subunit that can now phosphorylate substrate proteins and thereby alter their activity. This system is very versatile. There are a large number of known hormones, neurotransmitters, and local chemical mediators that can modify the activity of adenylyl cyclase, and there are a large number of poten- tial substrates that can be altered in their activity by cAMP-dependent protein kinase phosphorylation. The specificity of a given cellular response is determined by the selective expression of receptors and effectors in the responding cell.

The channeling of multiple signals to diverse effectors through a single intracellular signaling pathway appears to be a general principle of signal transduction and has important implications. In the extreme, it implies that eukaryotes only use a small number of cytoplasmic signal transduction molecules to mediate between transmembrane receptors and intracellular effectors and that these are multifunctional and ubiquitously expressed. This, in turn, argues that genes that reveal specific phenotypes owing to loss of function or that show cell-specific expression patterns are not likely to be involved in the central, cytoplasmic steps of signal transduction. Rather, investigation of the role of cytoplasmic signal transduction molecules in development requires a reverse genetic approach that targets known, multifunctional signaling molecules. PKA is the key mediator of the ubiquitous second messenger, CAMP, and is therefore a prime candidate for such an investigation. However, it must be emphasized that aside from some genetic studies in Dictyostelium (Simon et al. 1989; Firtel and Chapman 1990; Pitt et al. 1992; Simon et al. 1992), 
virtually all evidence concerning the mechanism and roles of cAMP-mediated signal transduction in multicellular eukaryotes to date derives from the study of fully differentiated cells. A genetic investigation of PKA function in Drosophila should indicate whether cAMP is also widely used during development of a metazoan and may provide a starting point for understanding molecular pathways underlying several developmental decisions that rely on intercellular communication.

The function of cAMP signaling in Drosophila has been approached previously by studying the phenotypes due to mutations in a cAMP phosphodiesterase type II gene (dunce) and a $\mathrm{Ca}^{2+}$ calmodulin-dependent adenylyl cyclase gene (rutabaga). Both dunce (dnc) and rutabaga (rut) mutations are nonlethal and were initially isolated on the basis of learning defects in mutant adult flies (Byers et al. 1981; Livingstone et al. 1984). In addition, somatic $d n c$ mutations can prevent egg-laying, and germ-line $d n c$ mutations lead to defects in early embryonic development that are partially suppressed by rut mutations (Bellen et al. 1987; Bellen and Kiger 1988). Loss-of-function mutations in each of these two genes lead to significant increases $(\mathrm{dnc})$ and decreases (rut) in ambient intracellular cAMP concentration, but in neither case abolish cAMP signaling because both adenylyl cyclase and phosphodiesterase activities are encoded by more than one gene. It might therefore be anticipated that the phenotypes observed for loss-of-function mutations of PKA would be more severe than those oberved for either $d n c$ or rut.

We have previously characterized a gene, $\mathrm{DC} 0$, that on the basis of DNA sequence is a Drosophila homolog of the catalytic subunit of mammalian PKA (Kalderon and Rubin 1988). Here, we report the isolation of mutations in the DCO gene, including null alleles. Measurements of PKA activity in mutant flies indicate that DCO is either the major or sole catalytic subunit gene in Drosophila. Large clones of cells, homozygous null for DC0, were generated in the eye at normal frequencies in mitotic recombination experiments, indicating that loss of DCO function does not lead to general cell autonomous lethality. However, DCO is required for viability of the whole organism as animals zygotically null for DCO die as morphologically normal, first-instar larvae. Adult females, heterozygous for a strong and a weak DC0 allele are sterile and show a striking defect in oogenesis that includes the development of egg chambers containing multinucleate nurse cells. Females that are heterozygous for two weak DCO alleles are fertile but show a maternal effect on embryonic development that encompasses a variety of phenotypes. Collectively, these results indicate that cAMP-dependent protein kinase is involved in mediating vital intercellular communications during oogenesis, embryogenesis, and larval development.

\section{Results}

\section{Isolation of deficiencies in the $30 \mathrm{C}$ region}

An overlapping set of deficiencies was generated in the region of the $\mathrm{DC} 0$ gene at $30 \mathrm{C}$ by making use of the marked transposons, TE16 $\left[\mathrm{w}^{+} \mathrm{rst}^{+}\right]$(Ising and Ramel 1976) and $\mathrm{P}\left[\left(\mathrm{W}^{+} r \mathrm{ry}^{+}\right) \mathrm{A}\right] \mathrm{N} 22$ (R. Levis, pers. comm.). A chromosomal walk of $180 \mathrm{~kb}$ surrounding the DC0 gene allowed us to position the transposons $60 \mathrm{~kb}$ distal to the DCO gene and to map the endpoints of several deficiency breakpoints that we generated, including $D f(2 L) T w 2$, $D f(2 L) \gamma 15, D f(2 L) \gamma 1$, and $D f(2 L) \gamma 27$ (Fig. 1). $D f(2 L) T w 2$ was one of 29 spontaneous excision derivatives of TE16 that had suffered similar, but nonidentical, deletions between the second DCO intron and the distal end of the TE transposon (Fig. 2). $D f(2 L) T w 2$ therefore retains all DCO coding sequences but lacks the final noncoding exon and behaves genetically as a hypomorphic DCO allele (see below). $D f(2 L) \gamma 15$ was derived from TE16 by $\gamma$-irradiation and lacks $80 \mathrm{~kb}$ from a position close to the DCO initiation codon to the distal end of the TE element (Fig. 2). It is therefore null for DC0 activity. Deficiency breakpoints outside of the cloned region of DNA were ordered relative to lethal and female sterile mutations in the 30A-C region, some of which were isolated in this study (Fig. 1).

\section{Lethal point mutations in the DCO gene}

An F2 screen (see Materials and methods) for ethylmethane sulfonate (EMS)-induced lethals uncovered by $D f(2 L) \gamma 15$ yielded two complementation groups. One [1(2)N7-6; 66 alleles from 3500 chromosomes] was complemented by deficiencies $\gamma 4, \gamma 25$ and TE2 but not by deficiencies $\gamma 1$ and $\gamma 27$ and, therefore, maps immediately distal to the DCO gene (Figs. 1 and 2). The second complementation group included 10 alleles, all of which complemented the deficiencies $\gamma 1$ and $\gamma 27$ (Fig. 2) and were shown to carry mutations in the DCO gene according to (1) rescue of viability with a DC0 transgene and (2) sequencing of the DCO coding region of mutant alleles. No recessive female sterile mutations mapping to the 80 -kb $D f(2 L) \gamma 15$ deletion interval were recovered by screening nonlethal F2 progeny from the above screen, indicating that $\mathrm{DCO}$ function cannot readily be altered to produce female sterility without effect on viability.

A transgene ( $\mathrm{TgDCO}$ ) consisting of genomic DNA from $2.8 \mathrm{~kb}$ upstream of the transcription start site to the termination codon of the DC0 gene, followed by an SV40 $3^{\prime}$-untranslated sequence and polyadenylation signal (Fig. 2), restored viability to each hemizygous allele. For two different integration sites, full rescue of several weak alleles $(\mathrm{A} 13, \mathrm{~B} 10, \mathrm{~B} 12)$ and partial rescue of strong alleles $(\mathrm{C} 2, \mathrm{C} 4 ; 40-50 \%$ viability) was obtained with a single copy of the transgene; two copies of $\mathrm{TgDCO}$ were required to restore appreciable viability to the strongest allele, B3 (one copy gave $<1 \%$ viability; two copies gave $83 \%$ viability), which is almost certainly a null (see below). Rescued animals were fertile and morphologically normal. Animals that were null for endogenous DC0 gene activity but contained two copies of the rescue transgene exhibited $\sim 20 \%$ of wild-type kinase activity (Fig. 3), indicating that $10 \%$ is the approximate threshold required for viability. 

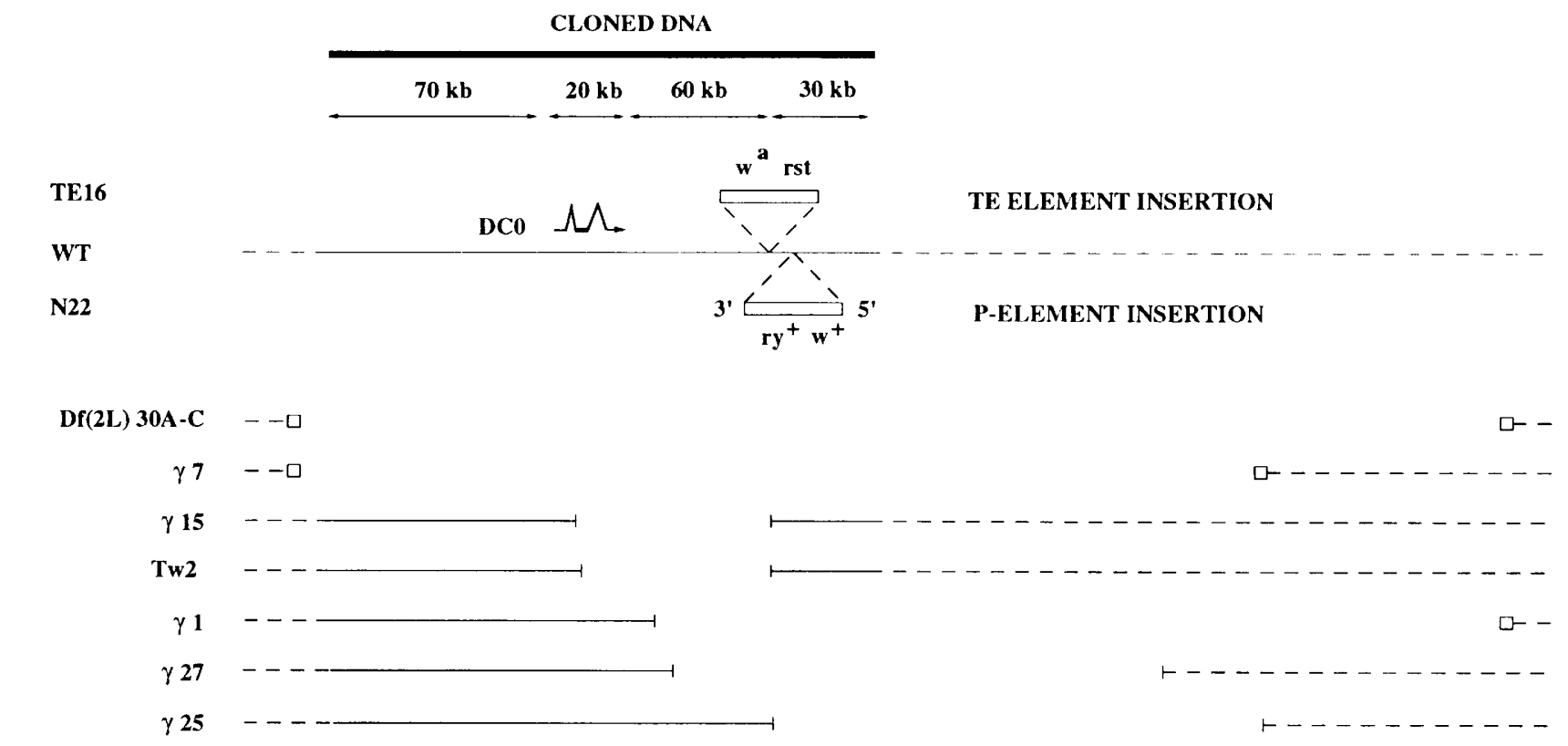

TE2 $, \gamma 4, \gamma 12, \gamma 29$

$166,169,210, \gamma 5$

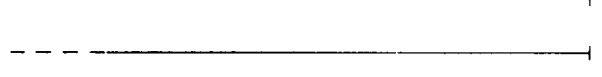

ㄴ-

$232-\square$

132, 176, 200, 255

50

A4

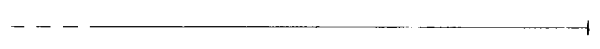

$+$

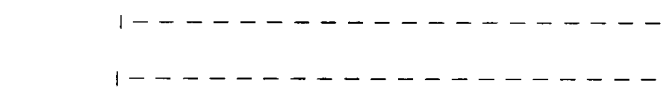

$-\ldots-\ldots \ldots \ldots-\ldots \ldots \ldots-\ldots-\ldots-\ldots-\ldots-\ldots-\ldots$

$1------$

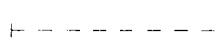

$$
\text { เ- }
$$

LETHALS \&

FEMALE STERILES

\section{1) I(2) $\mathrm{FE} 3$ \\ 2) 1(2) $\mathrm{DB} 2$}

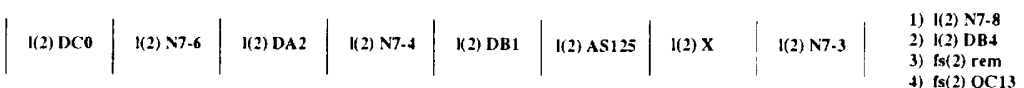

4) Is(2) QC13

PROXIMAL

30B

30A

DISTAL

Figure 1. The location of deficiency breakpoints generated in this study are depicted. At the top are shown the DCO transcription unit, the extent of a chromosomal walk, and the insertion sites of transposons in the stocks, TE16 $\left[w^{a}\right.$ rst $\left.^{+}\right]$transposon structure and orientation unknown (Ising and Ramel 1976) renamed TE30C, (Lindsley and Zimm 1992)] and P[|w ${ }^{+},{ }^{+}{ }^{+}|A| N 22$ (R. Levis, pers. comm.; also referred to as Isw030C; GR837). $D f(2 L) 30 A-C$ and DEB-induced lethals uncovered by that deficiency, $1(2) N 7-3,4,6,8$ (Uemura et al. 1989), $f s(2)$ rem, and $f_{s}(2) Q C 13$ (Schupbach and Weischaus 1989) have been described previously. Breakpoints (other than A4) within cloned DNA (solid lines) were determined by Southern blot; other breakpoints (broken lines) were inferred from complementation tests. All listed mutants were derived independently, and only a single representative of each complementation group is listed. Members of the lethal complementation groups FE3 $(3$ alleles), DB2 $(1), \mathrm{DC} 0(10), \mathrm{N} 7-6(66), \mathrm{DA} 2 \mid 6), \mathrm{DB} 1(1)$, and DB4(1) were induced by EMS in this study in an F2 lethal screen either over $D f(2 L) y 15(6000$ chromosomes screened) or over $D f(2 L) 30 A-C$ (1000 chromosomes screened). Neither this screen nor a previous screen (Uemura et al. 1989) over $D f(2 L) 30 A-C$ were close to saturation. The $1(2) \mathbf{x}$ complementation group is inferred from the lethality of $D f(2 L) 50$ over $D f(2 L) \gamma 25.1(2) A S 125$ [originally named 1(2)neo7] is a P transposon insertion in the numb gene at 30B (Uemura et al. 1989). The DC0 gene, the $\mathrm{P}\left[W^{+} r y^{+}\right]$insertion in stock N22, and the TE $\left[\mathrm{W}^{a} r s t^{+}\right]$insertion in stock TE16 all map to 30Cl-6; the $D f(2 L) 30 A-C$ has been defined more precisely as $D f(2 L) 30 A 3-6-$ 30D3-4 (B. Wakimoto, pers. comm.). Most of the chromosomes (including $D f(2 L) 30 A-C, \gamma 15, \gamma 25, \gamma 4,232,132,50)$ depicted appear by genetic and cytological criteria to be simple deficiencies, whereas $D f(2 L) \gamma 1$ and $\gamma 27$ additionally include translocations between the second and third chromosomes $[\gamma 1$ is $T(2 L ; 3 R[96 D 3-6])]$ : B. Wakimoto, pers. comm.]. $D f(2 L) T E 2$, Tw2, and 28, other stocks carrying deletions similar to Tw2, were derived from TE16 by spontaneous imprecise exisions of the TE transposon. $D f(2 L) \gamma 1-\gamma 29$ are $w^{-}$ derivatives of TE16 induced by $\gamma$-irradiation. $D F(2 L) 30 A-C$ is a $w^{-}$derivative of $\mathrm{N} 22$ induced by X-irradiation. The remaining deficiencies resulted from imprecise P-element excisions from a stock containing two $\mathrm{P}$ elements that was constructed as follows. First, a $w^{+} r y^{-}$derivative of N22 was recovered following hybrid dysgenesis. The resulting chromosome was then recombined with a chromosome from the stock S6.9-3 (also known as Isrt030C; AS365) that carried a $\mathrm{P}\left[\mathrm{ry}^{+}\right.$] insertion at $30 \mathrm{C}$ (that lies distal to the P element in $\mathrm{N} 22$ ) to give a $\mathrm{P}\left[\mathrm{w}^{+} r \mathrm{y}^{-}\right] \mathrm{P}\left[\mathrm{ry}^{+}\right]$derivative with two $\mathrm{P}$ elements. The imprecise excision products 132,200 , and 50 are $w^{+} r y^{-}, 169,176,210$ are $w^{-} r y^{+}, 255$ is $w^{-} r y^{-}$, and 166 is $r y^{-}$and has low $w^{+}$activity. 
Figure 2. Complementation properties of DC0 alleles. The location of three deficiency breakpoints close to the DC0 transcription unit are shown. $D f(2 L) \gamma 1$ does not affect the DCO transcription unit, $D f(2 L) \gamma 15$ removes almost the entire DCO-coding region, and $D f(2 L) T w 2$ breaks in the second DCO intron and removes the normal $3^{\prime}$ noncoding sequences. As $D f(2 L) T w 2$ behaves as a weak DCO allele, sequences distal to the deficiency presumably contribute a 3 ' end to DCO transcripts. Neither DCO alleles nor 1(2)N7-6 alleles complement $D f(2 L) \gamma 15$, whereas DC0 alleles but not 1(2)N7-6 alleles complement $D f(2 L) \gamma 1$. The $D C 0$ rescue transposon is shown above the DCO transcription unit. It includes $2.8 \mathrm{~kb}$ of genomic DNA upstream of the transcription initiation site and immediately after the translation termination codon is a sequence from SV40 (Thummel et al. 1988 ) that directs the synthesis of a short 3'-untranslated region and polyadenylation.

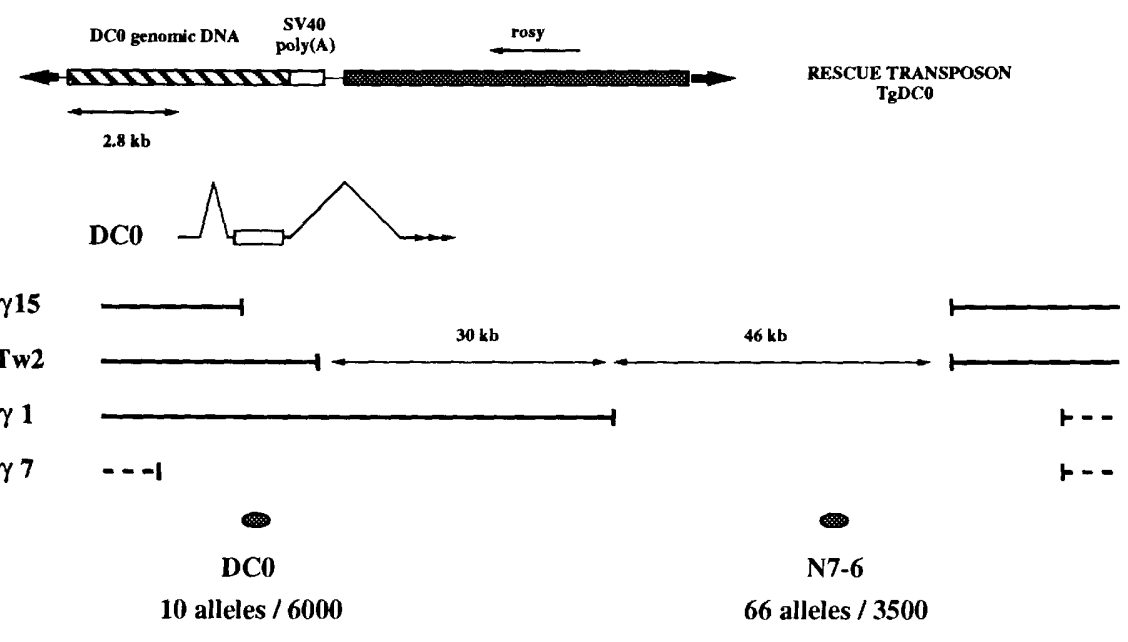

The DC0-coding sequence of each mutant allele was determined from PCR-amplified genomic DNA that had been separated electrophoretically from balancer chromosome DNA by taking advantage of an RFLP. In each case, a single point mutation was found that led to the creation of either a nonsense codon (B3, D30, G9) or a missense mutation (Table 1). Mutations resulting in strong alleles either produced a nonsense codon or affected residues that are highly conserved among all serine/threonine protein kinases (Hanks et al. 1988). We consider the B3 nonsense mutation to be a null as it truncates the encoded protein by $>50$ amino acids, does not encode any truncated protein stable enough to be detected in Western blots of B3 heterozygotes (data not shown), and behaves the same as $D f(2 L) \gamma 15$ in all phenotypic assays of DCO function.

\section{DCO encodes most, if not all, PKA activity in adult flies}

Although DCO is clearly the most similar Drosophila gene to mammalian cAMP-dependent protein kinase, two other genes, DC1 and DC2 (Kalderon and Rubin 1988), have been described that, from sequence considerations alone, could potentially encode alternative catalytic subunits of PKA. cAMP-dependent protein kinase activity was measured in crude extracts of adults for each heterozygous EMS-induced DCO allele and compared with that of the parental stock and deficiency derivatives. Flies heterozygous for each DC0 allele, $D f(2 L) \gamma 15$ and $D f(2 L) T w 2$, exhibited $\sim 50 \%$ of wild-type PKA activity (Fig. 3). This implies that the DCO gene is the source of all, or the majority, of measurable cAMPdependent protein kinase activity in Drosophila adults and that each mutant allele resulted in a drastic reduction in encoded activity. As DCO null mutations are lethal, we cannot exclude the possibility that genes other than DC0 make quantitatively minor contributions to PKA activity.

\section{Female sterility associated with DCO mutations}

The DCO alleles that we isolated fell into a phenotypic series that was defined initially by the lethal phase of hemizygotes (Fig. 6, below) and the limited ability of weak alleles to complement each other for viability. By these criteria, $D f(2 L) T w 2$ is the weakest DCO allele, as it showed some complementation of all other alleles, including a null (Table 1). Females that carry any of the stong alleles (B3, C2, C4, G9, and H2) of DC0 in trans to $D f(2 L) T w 2$ do not lay eggs. Dissection of ovaries from such females showed the presence of mature oocytes that were smaller than those from wild-type, fertile siblings. Examination of developing egg chambers by staining with Hoechst and rhodamine-conjugated phalloidin revealed a number of striking departures from the normal developmental pathway, including the formation of multinucleate nurse cells.

A normal egg chamber is composed of 16 germ line cells that are enveloped by a large number of mesodermally derived follicle cells (for review, see King 1970; Mahowald and Kambysellis 1980). The 16 germ-line cells result from four mitotic divisions of a single cell in the germarium. One of these cells differentiates into the oocyte, whereas the other 15 become polyploid nurse cells. Nurse cell nuclei are clearly visible in egg chambers stained with Hoechst, and the intensity of the staining increases with the age of the egg chamber, reflecting the increase in DNA content (Fig. 4A). All 16 cells remain interconnected through a series of cytoplasmic bridges that result from incomplete cytokineses. Filamentous actin ring canals are associated with these bridges and can be visualized by staining with rhodamine-conjugated phalloidin, which also reveals the actin cytoskeleton associated with the plasma membrane of all cells in the egg chamber (Fig. 4B; Warn et al. 1985). The first seven stages of oogenesis are characterized by coordinated volume increases of germ cells. During stage eight, the uptake of yolk proteins by the oocyte begins. By stage 10 , the oocyte occupies half the volume 


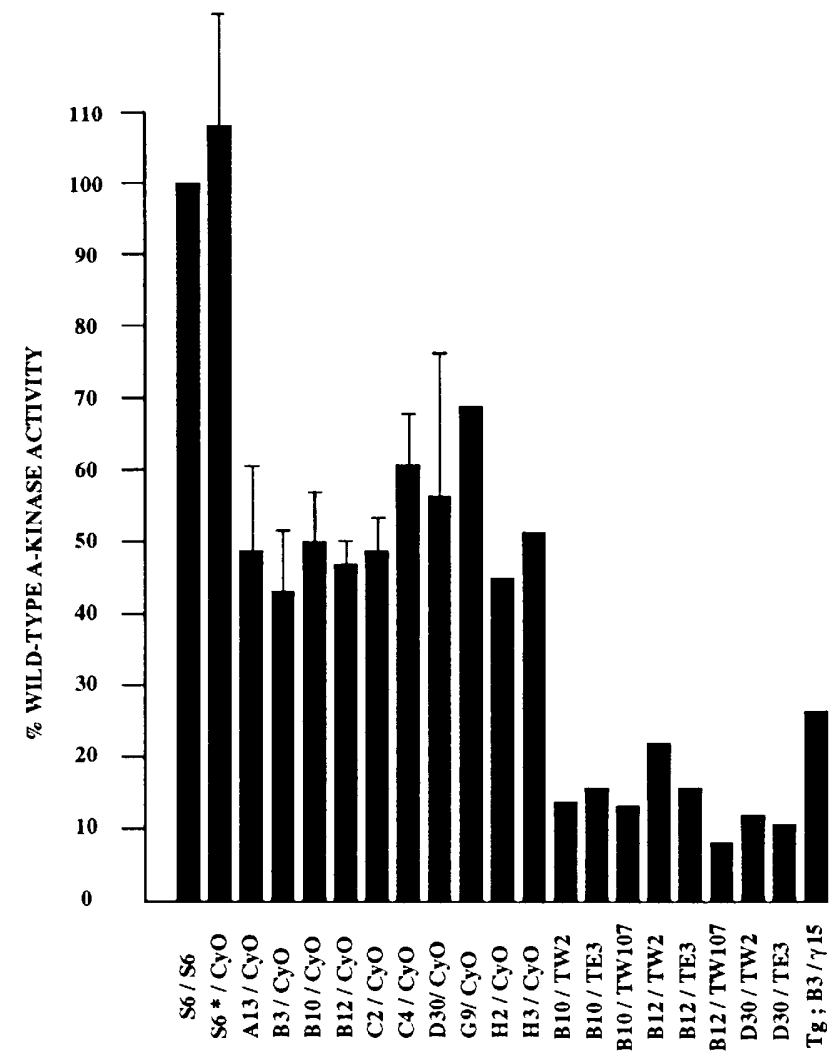

Figure 3. cAMP-dependent protein kinase activity in crude extracts was determined as described in Materials and methods. The kinase activity designated for $\mathrm{S}^{*} / \mathrm{CyO}$ is the average of four members of the 1(2)N7-6 complementation group that were isolated in the same F2 lethal screen as the DCO alleles and therefore expected to show wild-type PKA activity. Heterozygotes for each of the DC0 alleles (A13/CyO-H3/CyO) exhibited $\sim 50 \%$ the activity of wild-type parental flies (S6/S6). Each extract was assayed in duplicate; error bars are shown for those genotypes for which multiple $(2-5)$ extracts were assayed. $D f(2 L) \gamma 15(48 \%$ of control) and $D f(2 L) T w 2(35 \%$ of control relative to the parental genotype, TE16/CyO/ also showed at least a twofold reduction in kinase activity (not shown). Flies heterozygous for each of the alleles, B10, B12, and D30 and one of the deficiencies, $D f(2 L) T w 2, T E 3$, or $T w 107$, had severely reduced kinase activity (average, 14\% of wild-type) but did not show any clear phenotypic abnormalities. Kinase activity of flies of genotype $\mathrm{B} 10 / \mathrm{B} 12$ and $\mathrm{B} 12 / \mathrm{D} 30$ were assayed in the same experiments but were found to be too low to quantify and were therefore presumably below $15 \%$ of wild-type. Females of genotype $T g: B 3 / D f(2 L) \gamma 15$ contained two copies of the rescue transposon (TgDCO) on the $\mathrm{X}$ chromosome and were otherwise null for DC0 gene activity.

of the egg chamber and continues to grow as the nurse cells begin to transport their entire cytoplasmic contents into the oocyte. Transport is complete by stage 12 and is accompanied by the breakdown of nurse cell membranes, degeneration of nurse cell nuclei, and centripetal migration and degeneration of ring canals (Warn et al. 1985). Egg chambers from females trans-heterozygous for strong DC0 alleles and $D f(2 L) T w 2$ contained many egg chambers at stage five and beyond that included multinucleate nurse cells and defective ring canals.
The majority of mutant egg chambers contained 15 polyploid nuclei but $<15$ nurse cells oulined by phalloidin staning (Fig. 4C). The number of nurse cells per egg chamber ranged from 2 to 15 , although the majority of egg chambers beyond stage seven contained at least one multinucleate nurse cell. Nuclei within multinucleate nurse cells tended to be abnormally clustered, leaving large regions of cytoplasm devoid of nuclei (Fig. 4C, E, and G).

Although the majority of mutant egg chambers contained the normal number of ring canals (15), the morphology and distribution of ring canals was not normal. Some ring canals appeared smaller than normal, and others were not recognizable as rings but, rather, as dense bundles of filamentous actin. An egg chamber from a mutant female often contained both morphologically normal and abnormal ring canals. Abnormal ring canals tended to be associated with multinucleate cells, and often a number of abnormal ring canals were found close together in the middle of a multinucleate cell (Fig. $4 \mathrm{H}$ ), whereas normal ring canals were found associated with intact cell membranes. We have never observed a disruption of the plasma membrane or the ring canals that separates the oocyte from the four most posterior nurse cells. The penetrance and expressivity of the above phenotypes were quite variable. However, abnormal phenotypes were observed more frequently in later egg chambers. For example, there were many apparently normal stage five and stage six egg chambers from B3/Tw2 females, but by stage seven, the vast majority of egg chambers were affected. Egg chambers prior to stage five are sufficiently small that they could not be clearly classified as normal, although they have not been seen to contain clearly multinucleate cells or defective ring canals. Females trans-heterozygous for the weak allele, A13, and $D f(2 L) T w 2$ are fertile and show defects in oogenesis only in stage eight egg chambers and beyond, arguing that the egg chamber abnormalities that we observed are not attributable to egg retention per se and that they most likely result from the premature degeneration of nurse cells rather than aberrant cell divisions in the formation of the egg chamber.

Oogenesis was not found to be arrested in any of the mutant ovaries examined. Mature eggs of reduced size $(-75 \%$ of wild-type length) surrounded by a morphologically normal chorion were found in mutant ovaries, and G9/Tw2 females, in which the vast majority of egg chambers were affected by stage seven, showed limited egg-laying activity (one to two per day). These eggs were very fragile, and most embryos $(>80 \%)$ did not hatch or even make larval cuticle. One copy of the transposon, TgDC0 (Fig. 2) sufficed to rescue both the egg retention and egg chamber morphology phenotypes of $\mathrm{B} 3 / \mathrm{Tw} 2 \mathrm{fe}-$ males (data not shown).

\section{Limited embryonic lethality resulting from maternal DCO deficiency}

The four weakest EMS-induced alleles (B10, B12, D30, and $\mathrm{A} 13$ ) showed some intragenic complementation for 
Table 1. Complementation properties of DCO alleles

\begin{tabular}{|c|c|c|c|c|c|c|c|c|c|c|c|c|c|c|c|c|c|c|}
\hline \multirow[b]{3}{*}{ Allele } & \multirow{3}{*}{$\begin{array}{l}\text { Coding } \\
\text { change }\end{array}$} & \multicolumn{16}{|c|}{ Percent complementation } & \multirow{3}{*}{$\begin{array}{l}\text { Female } \\
\text { fertility } \\
\text { /Tw2 }\end{array}$} \\
\hline & & \multicolumn{4}{|c|}{$25^{\circ} \mathrm{C}$} & \multicolumn{4}{|c|}{$18^{\circ} \mathrm{C}$} & \multicolumn{4}{|c|}{$25^{\circ} \mathrm{C}$} & \multicolumn{4}{|c|}{$18^{\circ} \mathrm{C}$} & \\
\hline & & A 13 & D30 & B12 & $\mathrm{B} 10$ & $\mathrm{~A} 13$ & D30 & B12 & $\mathrm{B} 10$ & Tw2 & Tw6 & Tw107 & $\Sigma \mathrm{T}$ & Tw2 & Tw6 & Tw107 & $\Sigma \mathrm{T}$ & \\
\hline \multicolumn{19}{|l|}{ Null } \\
\hline B3 & $299 \mathrm{~W} \rightarrow$ Stop & 0 & 0 & 0 & 0 & 0 & 0 & 0 & 0 & 23 & 0 & 0 & 2 & 18 & 0 & 0 & 1 & no \\
\hline \multicolumn{19}{|l|}{ Strong } \\
\hline $\mathrm{H} 2$ & $203 \mathrm{G} \rightarrow \mathrm{D}$ & 0 & 0 & 0 & 0 & 0 & 0 & 0 & 0 & 14 & 0 & 0 & 1 & 18 & 0 & 0 & 2 & no \\
\hline G9 & $34 \mathrm{R} \rightarrow$ Stop & 0 & 0 & 0 & 0 & 0 & 0 & 0 & 0 & 25 & 0 & 0 & 2 & 23 & 0 & 0 & 5 & no \\
\hline $\mathrm{C} 4$ & $202 \mathrm{C} \rightarrow \mathrm{Y}$ & 0 & 0 & 0 & 0 & 0 & 0 & 0 & 0 & 28 & 0 & 0 & 2 & 22 & 0 & 0 & 2 & no \\
\hline $\mathrm{C} 2$ & $128 \mathrm{G} \rightarrow \mathrm{D}$ & 0 & 0 & 0 & 0 & 0 & 0 & 0 & 0 & 43 & 0 & 0 & 5 & 31 & 0 & 0 & 3 & no \\
\hline \multicolumn{19}{|c|}{ Medium } \\
\hline $\mathrm{H} 3$ & $200 \mathrm{~T} \rightarrow \mathrm{A}$ & 0 & 0 & 0 & 0 & 0 & 0 & 0 & 0 & 45 & 0 & 0 & 1 & 26 & 0 & 0 & 1 & yes \\
\hline \multicolumn{19}{|l|}{ Weak } \\
\hline A 13 & $186 \mathrm{~T} \rightarrow \mathrm{M}$ & 0 & 0 & 0 & 5 & 0 & 0 & 0 & 0 & 54 & 0 & 0 & 8 & 53 & 5 & 1 & 15 & yes \\
\hline D30 & $346 \mathrm{C} \rightarrow$ Stop & 0 & 0 & 17 & 27 & 0 & 0 & 0 & 1 & 64 & 19 & 8 & 37 & 73 & 25 & 41 & 65 & yes \\
\hline B12 & $128 \mathrm{G} \rightarrow \mathrm{S}$ & 0 & 17 & 0 & 33 & 0 & 2 & 0 & 0 & 84 & 33 & 28 & 52 & 97 & 78 & 66 & 87 & yes \\
\hline $\mathrm{B} 10$ & $219 \mathrm{~N} \rightarrow \mathrm{I}$ & 5 & 27 & 33 & 0 & 0 & 1 & 2 & 0 & 80 & 78 & 59 & 74 & 65 & 23 & 37 & 72 & yes \\
\hline
\end{tabular}

DNA sequencing of the coding region of the mutant $\mathrm{DC} 0$ alleles revealed the following mutations, underlying the tabulated amino acid changes: $\mathrm{A} 13(2680 \mathrm{C} \rightarrow \mathrm{T}), \mathrm{B} 3(3019 \mathrm{G} \rightarrow \mathrm{A}), \mathrm{B} 10(2779 \mathrm{~A} \rightarrow \mathrm{T}), \mathrm{B} 12(2505 \mathrm{G} \rightarrow \mathrm{A}), \mathrm{C} 2(2506 \mathrm{G} \rightarrow \mathrm{A}), \mathrm{C} 4(2728 \mathrm{G} \rightarrow \mathrm{A}), \mathrm{D} 30(3161$ $\mathrm{T} \rightarrow \mathrm{A}$ ), G9(2223 C $\rightarrow$ T), H2(2731 G $\rightarrow$ A), H3(2721 A $\rightarrow$ G) (numbering according to Kalderon and Rubin 1988). The same mutation as B10 was also found in two other alleles, D2 and D8, that may both derive from a single mutational event but arose independently of B10. The phenotypic properties of D2 and D8 were essentially identical to B10 and, therefore, are not reported here. The viability of various allelic combinations was determined by counting adult progeny resulting over a 10-day period from crosses between five pairs of heterozygotes (over $\mathrm{CyO}$ ) in a vial. The percentage viability is calculated as the number of non-CyO progeny divided by the number of CyO progeny and multiplied by 50. Similar figures were obtained from reciprocal crosses. The figures given are averages of many such experiments. The figures given in the columns $\Sigma T$ are averages for complementation tests using all 29 of the various $D f(2 L) T w 2$-like alleles and derive from a single experiment in which all 29 such alleles were used. $D f(2 L) T w 2$ represents one extreme of these alleles, being the weakest, whereas $D f(2 L) T w 6$ and $D f(2 L) T w 107$ are highlighted as being the strongest. Complementation of $D f(2 L)$ Tw2-like DC0 alleles appeared to be temperature independent, whereas complementation between two missense mutations was much reduced at $18^{\circ} \mathrm{C}$. The last column describes which alleles in trans to $D f(2 L) T w 2$ lead to female sterility. The EMS-induced DCO alleles are listed in order of a phenotypic series.

viability at $25^{\circ} \mathrm{C}$ but not at $18^{\circ} \mathrm{C}$ (Table 1$)$. Adult females, heterozygous for two weak alleles, were fertile and their ovaries showed no morphological abnormalities. However, their progeny hatched at lower rates $(45-55 \%)$ than progeny of control females $(>80 \%)$ (Table 2$)$. Similar hatching rates were observed whether females were crossed to $D f(2 L) \gamma 15$ heterozygotes or wild-type males (data not shown), indicating that the observed partially penetrant embryonic lethality could not be rescued by zygotic DC0 gene function. Examination of unhatched embryos revealed a variety of phenotypes, including disruption of the earliest events of embryogenesis.

A small percentage of the unhatched embryos proceeded far enough in development to secrete cuticle,

Figure 4. Female sterile alleles of DCO affect the structure of the developing egg chamber. Ovaries were dissected from wild-type and mutant females, fixed, and stained with Hoechst and rhodamine-conjugated phalloidin to visualize nuclei and filamentous actin. $(A, B)$ A wild-type stage 10 egg chamber stained with Hoechst to emphasize the regular spacing of the 15 polyploid nurse cell nuclei, and with rhodamine phalloidin showing cortical actin and actin ring canals. $(C, D)$ A stage 10 egg chamber from a G9/Tw2 female. One of the three cells in the focal plane contains at least five nuclei, whereas the other two appear to contain one each. Although the number and position of multinucleate cells was variable, the boundaries between the nurse cells and oocyte, as well as the ring canals associated with those membranes, were always intact. Actin networks, which normally form at this stage and extend from the cell cortex to the nuclear membrane, appear to be forming at the nurse cell-oocyte boundary. $(E, F)$ Ovariole of B3/Tw2 female. The effects of the mutation make accurrate staging difficult for previtellogenic stages. The youngest egg chamber shown is probably stage 5 or 6 , based on the density of nuclear staining. The other chambers are at stages 7 and 10. Nuclei are clustered, and regions free of nuclei are seen. This phenotype is not clearly visible before stage 4 or 5 . The cortical actin skeleton outlines large areas that appear to be multinucleate cells. The densely stained spots are presumed to correspond to ring canals that have degenerated (arrow). Normal ring canals are also present. $(G, H)$ Stage 7 chamber from B3/Tw2 mother, showing the relationship between defective ring canals and multinucleate cells. Four small and malformed actin rings are centrally located in a cell with four nuclei. This presumably reflects the absence of four cell membranes between these cells. It is not clear whether the defective ring canals are associated with the plasma membrane. The ring canals between the oocyte and posterior nurse cells appear to be normal. 
Developmental roles of Drosophila PKA

whereas the majority of unhatched embryos appeared to have arrested development earlier (Table 2). Examination of cuticles of unhatched embryos showed many de- fects, representatives of which are shown in Figure 5. These defects were quite variable and often difficult to classify. Least severely affected individuals showed only
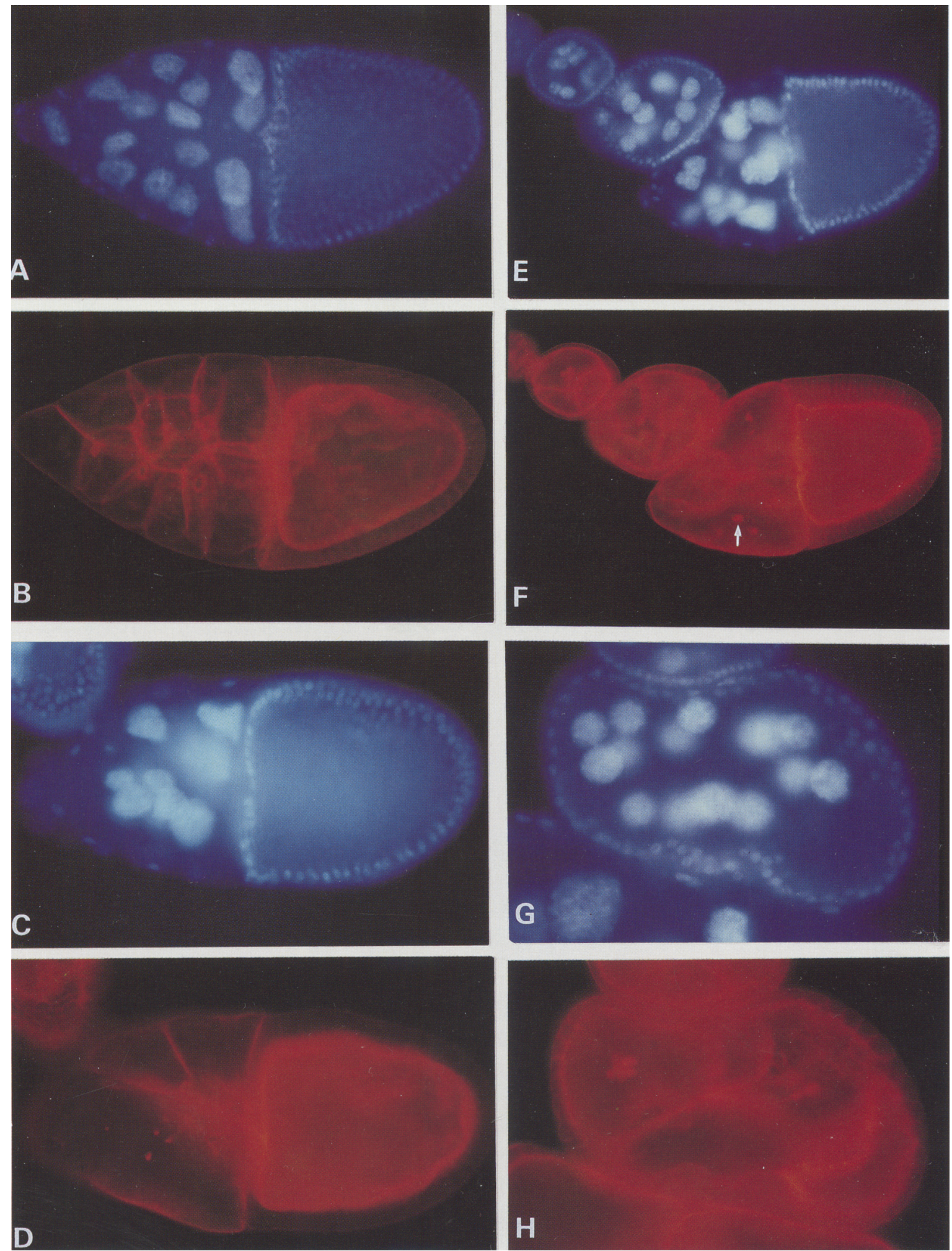

Figure 4. (See facing page for legend.) 
Table 2. Maternal effects of DCO mutations

\begin{tabular}{lccccc}
\hline $\begin{array}{l}\text { Maternal } \\
\text { genotype }\end{array}$ & $\begin{array}{l}\text { Individuals } \\
\text { scored }\end{array}$ & $\begin{array}{l}\text { Rate of } \\
\text { hatching }(\%)\end{array}$ & $\begin{array}{l}\text { Unfertilized } \\
\text { eggs }(\%)\end{array}$ & $\begin{array}{l}\text { Preblastoderm } \\
\text { arrest }(\%)\end{array}$ & $\begin{array}{l}\text { Cuticular patterning } \\
\text { defects }(\%)\end{array}$ \\
\hline A13/B10 & 750 & 45 & 32 & 8 & 15 \\
B12/B10 & 450 & 55 & 26 & 9 & 10 \\
D30/B10 & 800 & 53 & 29 & 5 & 10 \\
A13/S6 & 600 & 92 & 5 & 2 & 1 \\
B10/S6 & 800 & 90 & 5 & 0 & 0 \\
B12/S6 & 300 & 79 & 19 & 0 & 1 \\
D30/S6 & 500 & 94 & 5 & 0 \\
\hline
\end{tabular}

Females trans-heterozygous for two complementing alleles were crossed to $D f(2 L) \gamma 15 / C y O$ males to test the effects of reduced maternal kinase activity on embryonic viability. The lower panel shows results from control females, in which the mutagenized chromosome is in trans to the wild-type parental chromosome $(\mathrm{S} 6)$ to control for genetic background. Embryos were collected and counted, and the number of hatching progeny were determined after $36 \mathrm{hr}$ at $25^{\circ} \mathrm{C}$. Unhatched embryos were examined for cuticular defects. Embryos that did not show formation of cuticle were persumed to be unfertilized or arrested at early stages of development. To distinguish between these two classes, 5 to 16-hr collections were stained with Hoechst 33258 to visualize nuclei. Embryos with no observable nuclear staining were counted as unfertilized, and embryos that showed failure to reach cellular blastoderm or obvious defects in nuclear distribution and size were counted as preblastoderm arrest. Experiments were performed on two separate occasions and little variability was observed. Temperature and paternal genotype also did not appear to affect hatching rates (data not shown).

localized cuticular defects. In Figure 5B, for example, posterior abdominal segments and terminal structures appeared unaffected while parts of the anterior abdominal and thoracic segments were deleted and the cephalopharyngeal skeleton was abnormal. We also observed more severe alterations, as in Figure $5 \mathrm{C}$, that affected more than one region of the embryo or, as in Figure 5D, the gross morphology of embryos. In embryos that have abnormally high levels of cAMP owing to maternal mutations at the dnc locus, developmental defects were observed to be particularly pronounced in the posterior region of the embryo, even though cAMP levels were not found to vary significantly along the anterior-posterior axis (Bellen et al. 1987; Bellen and Kiger 1988; Whitehouse-Hills et al. 1992). Our observations did not indicate an enhanced sensitivity of any particular region to reduction in PKA activity. Although we did observe some cuticles that are specifically affected in posterior abdominal segments and terminal structures $(12 \%)$, in the majority of cases $(57 \%)$, defects were not limited to the posterior region, and in some cases $(31 \%)$ only anterior regions were affected.

To differentiate between unfertilized eggs and embryos that arrest early in development, collections of 5to 16-hr embryos were fixed and embryonic nuclei were visualized by staining with Hoechst (not shown). The absence of nuclear division in many embryos, usually about one-fourth of the total, indicated that they were unfertilized. Mutant females continued to deposit unfertilized eggs at this rate over a 2-week period; this behavior is unusual and was not seen with control heterozygous females (Table 2). In a small percentage of embryos,
Figure 5. Reduction in maternal kinase activity results in embryonic developmental defects. Representative larval cuticles from wild-type $(A)$ and transheterozygous DCO mutant mothers $(B-D)$ illustrating the variety of defects observed. In $(B)$, head defects and small deletion of parts of denticle bands in adjacent segment are present, whereas much of the embryo is unaffected. In $(C)$, defects in posterior abdominal segments are present (arrow) in addition to anterior defects. In $(D)$, the defects appear to be much more general.
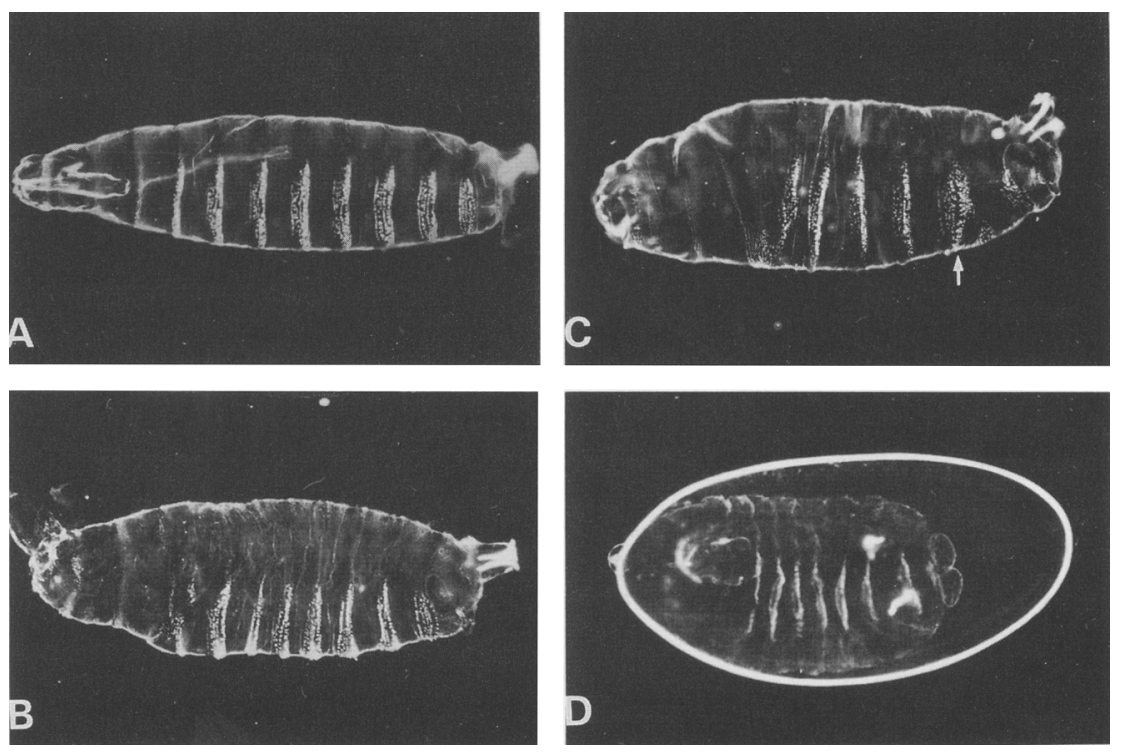
several cycles of nuclear division had taken place but development was apparently arrested prior to completion of syncytial nuclear divisions. Developmental arrest prior to cellularization has also been described for progeny of females mutant for $d n c$ in the germ line (Bellen et al. 1987).

\section{Larval lethality results from lack of zygotic DCO}

The lethal phase of animals hemizygous for each of the mutant DC0 alleles was examined to determine the earliest vital requirement for zygotic DCO activity. Hatching rates were normal for all DC0 alleles, including the presumed null, B3, and $D f(2 L) \gamma 15$ homozygotes, which are mutant not only for DCO but also for the adjacent lethal complementation group, 1(2)N7-6 (Fig. 6). Larvae that have no contribution of zygotic DCO gene activity are sluggish, do not molt or grow appreciably, and die within 2 days. However, no marked abnormalities were seen in their cuticles, central nervous systems, or peripheral nervous systems (data not shown). Larvae that have reduced DCO gene activity contributed by weak DCO alleles survived longer, often passed through one or two molts, and occasionally gave rise to pupae. In all cases, larval growth was considerably slower than that for heterozygous siblings; many larvae survived for periods up to 2 weeks before dying or pupating.

\section{Maternal DCO perdures for most of embryogenesis}

It seemed likely that embryogenesis proceeded normally in the absence of zygotic DCO because sufficient kinase

\begin{tabular}{|c|c|c|c|c|c|c|}
\hline \multicolumn{7}{|c|}{ LARVAL INSTAR } \\
\hline \multicolumn{2}{|r|}{ EMBRYO } & 1st & 2nd & 3 rd & PUPA & ADULT \\
\hline $\begin{array}{l}\text { B3, C4 } \\
\text { G9, H2 }\end{array}$ & & 1.0 & & & & \\
\hline C2 & & 1.4 & & & & \\
\hline $\mathbf{A 1 3}$ & & & & & $0.3 \%$ & \\
\hline D30 & & & 3.2 & & $1.1 \%$ & $0.4 \%$ \\
\hline B12 & & & & & $9 \%$ & $7 \%$ \\
\hline B10 & & & & 3.8 & $13 \%$ & $4 \%$ \\
\hline & All hatch & & $\begin{array}{l}\text { age nu } \\
\text { days a } \\
\text { s larv }\end{array}$ & & $\begin{array}{c}\% \\
\text { that rea }\end{array}$ & $\begin{array}{l}\text { nimals } \\
\text { this stage }\end{array}$ \\
\hline
\end{tabular}

Figure 6. The lethal phase was determined for each hemizygous DCO allele as described in Materials and methods. The percentage of hemizygous, $y^{-}$larvae that pupate and eclose was calculated for each allele, as was the average number of days larvae survived. All $y^{-}$larvae grew more slowly than their siblings so that many survived as larvae for several days beyond the normal time for pupation before they either died or pupated. The results shown were obtained at $25^{\circ} \mathrm{C}$. At $18^{\circ} \mathrm{C}$, the results were similar except that the average number of days larvae hemizygous for weak alleles survived were as follows: A13 14.0 days); D30 (5.5 days); B12 (5.3 days), and B10 (2.0 days). Thus, $\mathrm{B} 10$ hemizygotes fare significantly worse at $18^{\circ} \mathrm{C}$ compared with $25^{\circ} \mathrm{C}$. activity was encoded maternally. Northern analysis of poly $(\mathrm{A})^{+}$RNA extracted from staged embryos showed four DC0 transcripts present in 0- to 2-hr embryos (data not shown). These readily detected RNAs are almost certainly maternally derived as there is very little zygotic transcription in Drosophila embryos before $2 \mathrm{hr}$ of development (Edgar and Schubiger 1986). All four transcripts are present at other stages of development and have been described previously (Kalderon and Rubin 1988).

The perdurance of maternal DC0 protein was examined by staining progeny of $D f(2 L) \gamma 15$ heterozygotes with antiserum to DC0 at various stages of embryogenesis (data not shown). Abundant, ubiquitously distributed DC0 protein was detected in all embryos from the earliest stages until stage 14 (according to Campos-Ortega and Hartenstein 1985). After this time, approximately one-quarter of the embryos showed significantly weaker staining than their siblings; these are presumed to be $D f(2 L) \gamma 15$ homozygotes. Thus, DC0 protein translated from maternal mRNA was only appreciably depleted after $12 \mathrm{hr}$ and presumably sufficed to direct normal embryonic patterning.

\section{DCO mutations are not general cell autonomous lethals}

Mutations that inactiviate PKA in Saccharomyces cerevisiae preclude growth at a significant rate, whereas mutations that greatly reduce PKA activity in mammalian tissue culture cells have only modest effects on growth rate and do not reduce cell viability (Coffino et al. 1976; Toda et al. 1987). We investigated whether DC0 gene activity is required for cell viability or growth in Drosophila by generating mitotic clones in first-instar larvae and examining adult structures for clones of cells genetically deficient for DCO. Eye clones marked by the loss of the white gene were recovered both in a wild-type and a Minute background (Morata and Ripoll 1975) that slows the growth of competing nonrecombinant cells. In the latter case, the frequency with which clones were recovered and the number of cells within an average clone were comparable for all alleles of DCO tested, including nulls and the wild-type parent chromosome (Table 3). The morphology of five large clones homozygous for the null DC0 allele, B3, was examined in plastic sections and found to be normal (Fig. 7). As many of these clones contain $>500$ cells, the growth, differentiation, and continued survival of cells in the ommatidia do not appear to require significant levels of DC0 gene product. This implies that other developmental defects that we find associated with DC0 mutation are likely to result from disruption of cell-specific activities and not of essential processes common to all cells.

\section{Discussion}

In this study we have shown that cAMP-dependent protein kinase is required at multiple times during Droso- 
Table 3. Eye clones homozygous for DCO alleles are viable

\begin{tabular}{llc}
\hline & $\begin{array}{l}\text { Number } \\
\text { of clones per eye }\end{array}$ & $\begin{array}{l}\text { Clones } \\
>50 \text { ommatidia }\end{array}$ \\
\hline WT $($ S6) & $\frac{15}{296}=5.1 \%$ & $\frac{11}{15}$ \\
B3 & $\frac{13}{219}=5.9 \%$ & $\frac{5}{13}$ \\
C4 & $\frac{22}{233}=9.4 \%$ & $\frac{8}{22}$ \\
D30 & $\frac{5}{105}=4.8 \%$ & $\frac{5}{5}$
\end{tabular}

Progeny of a cross between heterozygotes for various $\mathrm{DCO}$ alleles and a balanced chromosome containing a Minute mutation and a marked $\mathrm{P}$ element at $30 \mathrm{C}$ (e.g., $w / w ; D C 0^{B 3} / C y O \mathrm{x}$ w; $P\left[\left(\mathrm{w}^{+} \mathrm{ry}^{+}\right) A\right]$ N22, $\left.\mathrm{M}(2) 201 / \mathrm{CyO}\right)$ were irradiated at $48-72 \mathrm{hr}$ after egg-laying with 1000 rads using a $\gamma$-ray source. Adult flies lacking the balancer chromosome were scored for the presence of $w^{-}$eye patches. Larvae from a cross between $w / w ; D C 0^{B 3}$ / $\mathrm{CyO}$ and $\left.\mathrm{w} ; \mathrm{P} / \mathrm{w}^{+} \mathrm{ry}^{+}(30 \mathrm{C} ; \mathrm{N22})\right]$ were irradiated in the same experiment to generate clones in a non-Minute background. In this case, clones appeared at similar frequency $(12 / 285=4.2 \%)$ but were generally smaller $\left(1 / 12>50\right.$ ommatidia). Most $w^{-}$ clones appeared grossly normal from the outside, with the exception of some large clones at the borders of the eye that were associated with alterations in the morphology of antennae and head capsule (D. Kalderon, unpubl.).

phila development. Loss-of-function mutations in the catalytic subunit, DC0, of Drosophila PKA led to female sterility, abnormal oogenesis, maternal effect embryonic lethality, or larval lethality, depending on the severity and the time of onset of dysfunction. Mitotic recombination experiments that examined clones deficient for DCO function in the eye indicated that DC0 is not generally required for viability or normal growth rates of individual cells, supporting the hypothesis that its primary function in development is to mediate communication between cells. Although the embryonic and larval lethal phenotypes observed probably result from simultaneous or cumulative disruption of multiple PKA-mediated processes, the production of multinucleate nurse cells and defective ring canals was seen in developing egg chambers of otherwise morphologically normal adult females and may therefore be the result of perturbation of a single PKA-mediated pathway. The phenotypes that result from DCO mutation may represent only a subset of PKA functions, as we cannot exclude the possibility that there are low amounts of catalytic subunits encoded by genes other than DCO. PKA activity measurements and nucleic acid hybridization studies (Kalderon and $\mathrm{Ru}$ bin 1988) do suggest, however, that Drosophila may differ from budding yeast and mammals in possessing only a single catalytic subunit gene.

$D C O$ is required for maintaining the structural integrity of cells that make up the egg chamber

The most striking consequence of altering PKA activity that we have observed is the formation of egg chambers with multinucleate nurse cells. This phenotype was seen at high penetrance in females heterozygous for strong alleles and $D f(2 L) T w 2$, which removes the normal $3^{\prime}$ end of the DC0 gene. No similar phenotypes have been described for other female sterile mutations, including $d n c$ mutations (Bellen and Kiger 1988; M.E. Lane and D. Kalderon, unpubl.) or mutations leading to degeneration of egg chambers and arrested oogenesis (Schupbach and Wieschaus 1991).

We believe that the multinucleate cells result from a premature breakdown of nurse cell membranes in midoogenesis. Although multinucleate cells could result from a failure of some of the cytokineses that generate the 15 nurse cells in an egg chamber, we consider this to be a less likely explanation for two reasons. First, aberrant egg chambers are only seen after stage 4 , and defects are more pronounced in older egg chambers. In females heterozygous for the weak allele, A13 and $D f(2 L) T w 2$, even stage 7 egg chambers were normal, whereas several egg chambers of stage 8 and beyond included multinucleate nurse cells. Second, we always observed 15 ring canals in early stage egg chambers. Because the ring canals are believed to be derived from cleavage furrows (Mahowald 1971) and therefore reflect the number of cleavages, this implies that the cell divisions in the germarium have taken place without disruption of the normal pattern of cytokinesis.

A number of aspects of the apparent breakdown of nurse cell membranes and structural defects of the ring canals resemble the changes that normally occur late in oogenesis at the time when the nurse cell cytoplasmic contents are being transported to the oocyte. Nurse cell membranes normally break down during stages 11 and



Figure 7. DCO function is not required for cell viability or development in the compound eye. Shown is a section through an adult eye containing a $W^{-}$clone that is homozygous for the B3 allele, a presumptive null. The $w^{-}$clone, which occupies most of the left side of this photograph, is recognizable by the lack of dark pigment granules. Although DCO is expressed in the larval eye disc (not shown), its function is not required for the viability or development of these cells. Each ommatidium contains the correct number and spatial arrangement of photoreceptors and accessory cells. 
12 (Cummings and King 1970); this is thought to contribute to the formation of a fast moving stream of cytoplasm (Gutzeit and Koppa 1982). At this stage, structural changes in the ring canals are also observed, including regression (Warn et. al. 1985). These changes occur in anterior nurse cells before they are seen in those nurse cells closest to the oocyte. Similarly, the structural abnormalities in egg chambers of females with DCO mutations most often affect anterior nurse cells and associated ring canals. One hypothesis to be entertained is that PKA dysfunction is leading to premature nurse cell regression owing to a disruption in the normal temporal coordination of events during oogenesis. Another possibility is that PKA is required to maintain the normal cytoskeletal architecture of the egg chamber. Several mammalian proteins have been described that bind to the type II regulatory subunit of PKA and may serve to localize kinase activity to the neighborhood of cytoskeletal components (Theurkauf and Vallee 1982; Carr et al. 1992; Glantz et al. 1992). Although we see rearrangement of cortical actin and of ring canals to accommodate fusion of nurse cells and an irregular distribution of nuclei within multinucleate nurse cells, these nuclei must still be held in place by the cytoplasmic actin network, as the streaming of cytoplasm from nurse cell to oocyte is not blocked by free-flowing nuclei as has been observed in the chickadee mutation, which affects the actin and phospholipid-binding protein profilin (Cooley et al. 1992).

\section{Maternally provided DCO is necessary and sufficient for normal embryogenesis}

Animals totally deficient for zygotic DCO function hatched at normal rates and appeared morphologically normal. Maternally encoded DCO protein, which persists at high levels for at least $12 \mathrm{hr}$ postfertilization, is, however, required for normal embryogenesis. The most prevalent maternal-effect phenotype is a developmental arrest prior to cellularization that is not rescued by zygotic DCO activity. This may reflect a defect in oogenesis or early embryogenesis. The cuticular defects observed in older embryos do not show a clear resemblance to any single class of zygotic patterning mutation. It may be that PKA is required for many embryonic patterning processes, each of which is only partially disrupted by the hypomorphic alleles used in these experiments. Alternatively PKA may not play an essential role in embryonic patterning. Resolution of this issue requires the use of conditional alleles or other means to manipulate embryonic PKA activity without affecting essential PKA functions in oogenesis.

\section{Postembryonic functions of $D C O$}

Animals with half the normal maternal contribution of DC0 and zygotically null for DCO die as normally patterned first-instar larvae. We presume, therefore, that $z y-$ gotic DC0 plays no essential role in embryogenesis, but we do not know why these animals die as larvae. Their central and peripheral nervous systems are morphologically normal, they move toward food, although sluggishly, and they respond to a mechanical stimulus (W. Li and D. Kalderon, unpubl.). A requirement for wild-type DC0 activity to maintain normal larval growth rates is also apparent, being most obvious for weak alleles that allow the slow maturation of larvae for periods up to 2 weeks before pupation or death. Animals that are heterozygous for two weak DC0 alleles often survive to adulthood but, in general, do not show external morphological abnormalities. Thus, the vital requirement of the whole organism for DC0 activity appears to exceed that for the correct development of any particular imaginal structure.

\section{A DCO null allele is not a cell autonomous lethal in the eye}

Eye clones carrying homozygous DC0 alleles, including the null, B3, could be induced by mitotic recombination in both a wild-type and a Minute background (Morata and Ripoll 1975) at frequencies equivalent to wild-type clones, indicating that $\mathrm{DC} 0$ gene function is not required for viability in these cells. Furthermore, the distribution of clone sizes was similar for wild-type and mutant DC0 alleles, indicating that DCO gene function is also not required to support normal growth rates in ommatidial precursor cells. As many of the clones recovered in this study included $>500$ cells and because clones were scored at least 10 days after induction, it is extremely unlikely that significant amounts of DCO mRNA or protein perdure from the original cell suffering mitotic recombination. The apparent lack of a requirement for DC0 for growth, viability, or normal development in this group of cells suggests that $\mathrm{DCO}$ is not required for processes that are common to all cells. In $S$. cerevisiae a vital requirement for PKA can be supported by a very low level $\mid<1 \%)$ of constitutive PKA activity or by the overexpression of another protein kinase (Cameron et al. 1988; Toda et al. 1988; Gibbs and Zoller 1991b). By analogy, it is possible that in Drosophila, PKA functions primarily by responding to extracellular signals but that it is also required at extremely low levels for an essential housekeeping function. This low housekeeping activity may be provided by perduring $\mathrm{DC} 0$ in these mitotic recombination experiments or, perhaps, by another protein kinase. In any case, the levels of DCO activity that give rise to aberrant oogenesis, maternal effects on embryogenesis, larval growth restrictions, and larval lethality far exceed those that support growth, development, and survival of individual cells in the adult eye.

\section{DCO encodes the major catalytic subunit of Drosophila PKA}

Multiple genes have been found to encode PKA catalytic subunit activity in budding yeast and mammals (Toda et al. 1987; Beebe et al. 1990). We believe that the DC0 gene encodes the major catalytic subunit of PKA in Drosophila based on two observations. First, all DC0 alleles 
were lethal over a deficiency for the region. This indicates that the gene encodes an essential, nonredundant function. This differs from the situation in S. cerevisiae, where any one of the three TPK genes is sufficient for normal growth and viability (Toda et al. 1987). Second, extracts from animals that are heterozygous for a mutant DCO allele, including a deficiency, showed half the wildtype level of in vitro PKA activity. It is unlikely that any putative alternative catalytic subunit would evade detection in our assays because of altered substrate specificity because even the two most widely divergent catalytic subunits studied to date $\mid S$. cerevisiae TPK1 and mouse $\mathrm{C} \alpha ; 50 \%$ amino acid identity) show identical substrate specificities (Gibbs and Zoller 1991a). Although it is possible that the contribution of other putative catalytic subunits was not measured because their activity is very low or because they are not expressed in adults, the two known candidate catalytic subunit genes, $\mathrm{DC} 1$ and $\mathrm{DC} 2$, are both expressed maximally in adults, producing RNAs of similar abundance to DCO (Kalderon and Rubin 1988).

\section{Signal transduction molecules in development}

Besides these studies concerning the role of cAMP in Drosophila, there have been very few investigations of the involvement of conventional intracellular second messengers in development. Multicellular development in Dictyostelium is induced by an extracellular cAMP signal and uses a variety of second messengers, including intracellular cAMP, to effect aggregation and changes in gene expression (Simon et al. 1989; Firtel and Chapman 1990; van Haastert et al. 1991; Pitt et al. 1992; Simon et al. 1992). Systematic genetic approaches to cell communication processes in Drosophila development have not, in general, revealed the identity of signal transduction molecules through conventional screens for specific loss-of-function phenotypes. Progress in following signal transduction pathways has recently been made through genetic screens that assume signal transduction molecules will be multifunctional (Simon et al. 1991), in this case revealing a role for ras in mediating signals from activated transmembrane tyrosine kinases. This and other recent observations (Firtel and Chapman 1990; Otte et al. 1991; Sternberg and Horvitz 1991; Livingston and Wilt 1992; Simon et al. 1992) lend support to the view that signal transduction in developing cells uses similar pathways to those used in differentiated cells and that the specificity of information that is relayed depends on selective expression of receptors and effectors, either side of a ubiquitously expressed core of cytoplasmic signal transduction molecules. It is therefore essential to investigate further the role of signal transduction molecules like cAMP in development. Our studies in Drosophila have established that the major catalytic subunit of PKA is not required for the growth and viability of individual cells but is required for normal oogenesis, embryogenesis, and postembryonic development. In particular, we have shown that reduction in PKA activity can lead to the generation of a novel oogenesis phenotype that promises to reveal information about cytoskeletal regulation or the coordination of events during egg chamber maturation. Further insight into embryonic functions of cAMP, such as its possible involvement in dorsal activation (Norris and Manley 1992), will require conditional alleles or the use of selectively expressed PKA inhibitors to circumvent the earlier requirements for PKA activity.

\section{Materials and methods}

\section{Isolation of mutant DCO alleles}

w; TE16 males (Ising and Ramel 1976) were $\gamma$-irradiated (5000 rads), $2-5$ days posteclosion and mated to $w^{1118} ; S c o / C y O$ virgin females (Lindsley and Zimm 1992). Balanced stocks (over $\mathrm{CyO}$ ) were made from all $\mathrm{w}^{-}$derivatives. Those carrying deficiencies in the $30 \mathrm{C}$ region were identified by Southern blot using probes either side of DC0 that detect RFLPs. The probes were derived from a chromosomal walk of $180 \mathrm{~kb}$ that was constructed from two different genomic $\lambda$ phage libraries [Canton-S in Charon 4A (Maniatis et al. 1978); Canton-S in EMBL4 [V. Pirrotta, unpubl.)] and mapped with six restriction enzymes. Spontaneous excision derivatives of TE16 were isolated by the same procedure but without recourse to irradiation. In both cases, $w^{-}$derivatives were isolated at a frequency of $\sim 1$ in 500 . For the F2 lethal screen, isogenized S6.9.3; ry ${ }^{506}$ (Isrt030C; AS365) males were fed $25 \mathrm{~mm}$ EMS in $1 \%$ sucrose, $10 \mathrm{~mm}$ Tris (pH 7.5) as described (Grigliatti 1986) and mated to Sco/CyO; $\mathrm{ry}^{506}$ virgin females. Male progeny were mated individually to $D f(2 L) \gamma 15 / C y O ; r y^{506}$ virgin females. In vials yielding only curly-winged progeny, a balanced stock was derived for $\mathrm{ry}^{+}$ flies. All lethal mutations were found, by outcrossing to a $\mathrm{ry}^{506}$ stock, to be closely linked to the $\mathrm{P}\left[\mathrm{ry}^{+}\right]$insertion of 56.9 .3 at $30 \mathrm{C}$.

\section{Germ-line transformation}

A 5.5-kb BamHI-XbaI fragment of genomic DNA from the DCO region extending from $2.8 \mathrm{~kb}$ upstream of the transcription start to the stop codon was cloned into pHSS7 (Mismer and Rubin 1987) adjacent to an 800-bp XbaI-EcoRI fragment carrying the SV40 T antigen polyadenylation signal (Thummel et al. 1988). From this construct, a NotI fragment containing the entire DC0 genomic fragment and SV40 DNA was cloned into pDM30 (Mismer and Rubin 1987). DNA was injected with helper plasmid pUChsp $\Delta 2-3$ into $r y^{506}$ embryos as described (Rubin and Spradling 1982). Two independent transformants were tested for the ability to rescue the lethality associated with point mutations over $D f(2 L) \gamma 15$.

\section{Sequencing of mutant alleles}

Genomic DNA from flies heterozygous for each DC0 allele and the TE16 chromosome were digested with HindIII, and fragments of $\sim 3.6 \mathrm{~kb}$, deriving from the chromosome carrying the mutant DC0 genes, were gel purified (the DC0 gene from the TE16 chromosome migrates in a 9-kb HindIII fragment). Fragments containing DC0-coding sequence were amplified using the primers, Pre-Sac (GGATATTCAGCGAATAAG; 1646-1664; numbering from Kalderon and Rubin 1988) and Post-Xba (TGCAGAACGAAGGGGATT; 3225-3207; numbering from Kalderon and Rubin 1988) and cloned as SacI-XbaI fragments into pBluescript $\mathrm{KS}^{-}$) (Stratagene). The DNA sequence of the DC0coding region was determined using oligonucleotide primers and equimolar pools of five rescued single-stranded templates 
for each allele. Mutations present in the fly genome were distinguished in every case from PCR, sequencing, and cloning artifacts by their presence in clones derived from two independent PCR amplifications and in both individual and pooled single-stranded templates.

\section{Kinase assays}

Kinase assays were performed essentially as described (Cobb and Corbin 1988). Extracts were made by homogenization of 20 adult males in $200 \mu \mathrm{l}$ of buffer A (10 mM sodium phosphate at pH 6.8, 1 mM EDTA, 0.5 mM EGTA, $2.5 \mathrm{~mm}$ 2-mercaptoethanol, $25 \mathrm{~mm}$ benzamidine, $1 \mathrm{mM}$ PMSF) and centrifuged at $10,000 \mathrm{~g}$ for $10 \mathrm{~min}$. Thirty-five microliters of extract supernatant was assayed in a total volume of $50 \mu \mathrm{l}$ containing $50 \mathrm{mM}$ MOPS at $\mathrm{pH} 7.0,10 \mathrm{mM} \mathrm{MgCl}_{2}, 0.25 \mathrm{mg} / \mathrm{ml}$ of BSA, $0.1 \mathrm{~mm}$ Kemptide, and $0.1 \mathrm{mM}\left[\gamma^{32} \mathrm{P}\right]$ ATP $(5 \mathrm{Ci} / \mathrm{mmole})$, with or without $10 \mu \mathrm{M}$ cAMP at $30^{\circ} \mathrm{C}$. Incorporation of label into the substrate was measured by spotting onto Whatman P81 paper and washing $(3 \times 2 \mathrm{~min})$ in $75 \mathrm{~mm}$ phosphoric acid, using seven time points in a $2 \mathrm{~min}$. reaction to calculate reaction rate. Protein concentration of extracts was determined using the Bio-Rad reagent (Bradford 1976).

\section{Mitotic recombination to produce eye clones}

Progeny of a cross between heterozygotes for various DC0 alleles $\left(\mathrm{W}^{1118} ; D C 0^{\mathrm{x}} / \mathrm{CyO}\right)$ and a stock containing a $\mathrm{P}\left[\mathrm{w}^{+}\right]$element at $30 \mathrm{C}\left(w^{1118}, N 22\right)$ or the $\mathrm{P}\left[w^{+}\right]$element and a Minute mutation ( $\left.w^{1118} ; M(2) 201, N 22 / C y O\right)$ were irradiated (1000-rad $\gamma$-rays) 48-72 hr after egg-laying. Adult flies lacking the CyO balancer chromosome were scored for the presence of $w^{-}$eye patches, and eyes with large clones were fixed and sectioned (Tomlinson and Ready 1987).

\section{Lethal phase analysis}

A $\mathrm{P}\left[y^{+}\right]$transposon, initially located on the third chromosome, was mobilized and an insertion on the CyO chromosome was recovered. All DCO mutant alleles and $D f(2 L) \gamma 15$ were crossed into a $y w^{a}$ background and placed over the marked, $\mathrm{P}\left[\mathrm{y}^{+}\right] \mathrm{CyO}$, chromosome. From crosses between such mutant DC0 alleles and $D f(2 L) \gamma 15$ stocks in egg collection chambers, $y^{-}$larvae, hemizygous for each DCO allele could be counted relative to siblings and transferred to fresh yeasted apple juice plates, where the numbers of dead and living larvae, pupae, and adults were counted daily.

\section{RNA isolation and analysis}

Embryos were collected from large population cages of wildtype (Oregon-R) flies and aged for the appropriate length of time. Embryos were washed, frozen in liquid nitrogen, and stored at $-70^{\circ} \mathrm{C}$. RNA was extracted as described (Sambrook et al. 1989). Northern analysis of RNA run on formaldehyde gels and blotted onto GeneScreen Plus (New England Nuclear) was conducted according to standard procedures.

\section{Preparation of antibody}

A DCO cDNA, modified to contain an EcoRI and a KpnI site immediately upstream of the initiation codon /to give a sequence ...GTCATCGCTAACGAATTCAGGTACCAAAATG. . . .) was cloned into the $\mathrm{T} 7$ expression vector, $\mathrm{pAR} 3040$ (Studier and Moffatt 1985), which was modified to include a KpnI site immediately downstream of the Shine-Dalgarno sequence (to give a sequence ... AAGGAGGTACCCATATG ....). Protein was purified by sedimentation of inclusion bodies followed by electroelution after SDS-PAGE and used to immunize rabbits. Rabbit serum was purified using DC0 protein immobilized on nitrocellulose as described by Harlow and Lane (1988).

\section{Antibody staining of embryos}

Embryos were collected from large population cages of $D f(2 L) \gamma 15 /$ $\mathrm{CyO}$ flies on yeasted apple juice plates and aged for the appropriate length of time. Embryos were fixed as described by Frasch et al. (1987). HRP immunocytochemistry was done as described by Patel et al. (1987), except that biotinylated secondary antibodies and avidin-HRP came from the Vector Elite ABC kit (Vector Labs). Primary antibody was diluted $1: 400$.

\section{Determination of hatching rates}

Virgin females of the appropriate genotypes were collected, aged for 2 days, and crossed to males that were $D f(2 L) \gamma 15 / C y O$. Embryos were collected daily on apple juice plates with wet yeast, aged for $36 \mathrm{hr}$, and progeny were counted. Cuticles of unhatched embryos were prepared according to Ashburner (1989). For examination of nuclei, embryos were collected for $8 \mathrm{hr}$, aged for 4 $\mathrm{hr}$, fixed as for antibody staining, and stained with Hoechst 33258 (Sigma) at a concentration of $1 \mathrm{mg} / \mathrm{ml}$ for $10 \mathrm{~min}$.

\section{Analysis of ovaries}

Adult flies ( 1 to 2 days old) were fed wet yeast for 2-3 days. Ovaries were dissected in cold $1 \times$ PBS and fixed in a $1: 1 \mathrm{mix}-$ ture of $4 \%$ paraformaldehyde and heptane for $10 \mathrm{~min}$. After three washes in PBS $+0.1 \%$ Tween (PBT), ovaries were stained with Hoechst 33258 as described above or for $20 \mathrm{~min}$ in $10 \mathrm{ml}$ of rhodamine-conjugated phalloidin (molecular probes R-415), which was dried and resuspended in $200 \mathrm{ml}$ of PBT. Ovaries were washed overnight in PBT and mounted in p-phenylenediamine/glycerol mountant (Ashburner 1989).

\section{Acknowledgments}

We thank Luzminda Barzaga for excellent technical assistance in this work, Nick Baker, Tulle Hazelrigg, Jym Mohler, Steve Mount, and Andrew Tomlinson for extremely useful comments on the manuscript; Judy Hull and Nick Necles for invaluable help in preparing the manuscript and photographs; and our laboratory colleagues, Willis $\mathrm{Li}$ and Alicia Melendez. This work was supported by a predoctoral training grant from the National Institutes of Health (NIH) to M.E.L. and NIH grant GM41815 and a Pew Scholars Award to D.K.

The publication costs of this article were defrayed in part by payment of page charges. This article must therefore be hereby marked "advertisement" in accordance with 18 USC section 1734 solely to indicate this fact.

\section{References}

Ashburner, M. 1989. Drosophila: A laboratory manual. Cold Spring Harbor Laboratory Press, Cold Spring Harbor, New York.

Beebe, S.J., O. Oyen, M. Sandberg, A. Froysa, V. Hansson, and T. Jahnsen. 1990. Molecular cloning of a tissue specific protein kinase $(\mathrm{C} \gamma)$ from human testis, representing a third isoform for the catalytic subunit of cAMP-dependent protein kinase. Mol. Endocrinol. 4: 465-475. 
Bellen, H.J. and J. A. Kiger Jr. 1988. Maternal effects of general and regional specificity on embryos of Drosophila melanogaster caused by dunce and rutabaga mutant combinations. Wilhelm Roux's Arch. Dev. Biol. 197: 258-268.

Bellen, H.J., B.K. Gregory, C.L. Olsson, and J.A. Kiger Jr. 1987. Two Drosophila learning mutants, dunce and rutabaga, provide evidence for a maternal role for cAMP in embryogenesis. Dev. Biol. 121: 432-444.

Bradford, M.M, 1976. A rapid and sensitive method for the quantitation of microgram quantities of protein utilizing the principle of protein-dye binding. Anal. Biochem. 72: 248254.

Byers, D., R.L. Davis, and J.A. Kiger. 1981. Defect in CAMP phosphodiesterase due to the dunce mutation of learning in Drosophila melanogaster. Nature 289: 79-81.

Cameron, S., L. Levin, M. Zoller, and M. Wigler. 1988. cAMPindependent control of sporulation, glycogen metabolism and heat shock resistance in S. cerevisiae. Cell 53: 555-566.

Campos-Ortega, J.A. and V. Hartenstein. 1985. The embryonic development of Drosophila melanogaster. Springer-Verlag, Berlin/New York.

Carr, D.W., R.E. Stofko-Hahn, I.D.C. Fraser, R.D. Cone, and J.D. Scott. 1992. Localization of the cAMP-dependent protein kinase to the postsynaptic densities by A-Kinase Anchoring Proteins. J. Biol. Chem. 267: 16816-16823.

Cobb, C.E. and J.D. Corbin. 1988. Purification of cAMP-free and cAMP-bound forms of bovine heart CAMP-dependent protein kinase holoenzyme. Methods Enzymol. 159: 202-208.

Coffino, P., H.R. Bourne, U. Freidrich, J. Hochman, P.A. Insel, I. Lemaire, K.L. Melmon, and G.M. Tomkins. 1976. Molecular mechanisms of cyclic AMP action: A genetic approach. $R e$ cent Prog. Horm. Res. 32: 669-684.

Cooley, L., E. Verheyen, and K. Ayers 1992. Chickadee encodes a profilin required for intercellular cytoplasm transport during Drosophila oogenesis. Cell 69: 173-184.

Cummings, M. and R.C. King. 1970. Ultrastructural changes in nurse and follicle cells during late stages of oogenesis in Drosophila melanogaster. Z. Zellforsch. 110: 1-8.

Dhallan, R.S., K.-W. Yau, K.A. Schrader, and R.R. Reed. 1990. Primary structure and functional expression of a cyclic nucleotide-activated channel from olfactory neurons. Nature 347: 184-187.

Edgar, B.A. and G. Schubiger. 1986. Parameters controlling transcriptional activation during early Drosophila development. Cell 44: 871-877.

Firtel, R.A. and A.L. Chapman. 1990. A role for cAMP-dependent protein kinase in early Dictyostelium development. Genes \& Dev. 4: 18-28.

Frasch, M., T. Hoey, C. Rushlow, H.J. Doyle, and M. Levine. 1987. Characterization and localization of the even-skipped protein of Drosophila. EMBO J. 6: 284-289.

Gibbs, C.S. and M.J. Zoller. 1991a. Identification of electrostatic interactions that determine the phosphorylation site specificity of the cAMP-dependent protein kinase. Biochemistry 30: 5329-5334.

- 1991b. Rational scanning mutagenesis of a protein kinase identifies functional regions involved in catalysis and substrate interactions. J. Biol. Chem. 266: 8923-8931.

Gilman, A.G. 1984. G proteins and dual control of adenylate cyclase. Cell 36: 577-579.

Glantz, S.B., J.A. Amat, and C.S. Rubin. 1992. cAMP signaling in neurons: Patterns of neuronal expression and intracellular localization for a novel protein, AKAP 150, that anchors the regulatory subunit of cAMP-dependent protein kinase II $\beta$. Mol. Biol. Cell 3: 1215-1228.

Grigliatti, T. 1986. Mutagenesis. In Drosophila, a practical ap- proach (ed. D.B. Roberts), pp. 39-58. IRL Press, Oxford, UK. Gutzeit, H.O. and R. Koppa. 1982. Time-lapse film analysis of cytoplasmic streaming during late oogenesis of Drosophila. I. Exp. Embryol. Morphol. 67: 101-111.

Hanks, S.K., A.M. Quinn, and T. Hunter. 1988. The protein kinase family: Conserved features and deduced phylogeny of the catalytic domains. Science 241: 42-52.

Harlow, E. and D. Lane. 1988. Antibodies: A laboratory man ual. Cold Spring Harbor Laboratory, Cold Spring Harbor, New York.

Ising, G. and C. Ramel. 1976. The behaviour of a transposing element in Drosophila melanogaster. In The genetics and biology of Drosophila (ed. M Ashburner and E. Novitski), Vol. 1b, pp. 947-954. Academic Press, London/New York.

Kalderon, D. and G.M. Rubin. 1988. Isolation and characterization of Drosophila cAMP-dependent protein kinase genes. Genes \& Dev. 2: 1539-1556.

King, R.C. 1970. Ovarian development in Drosophila melanogaster. Academic Press, New York.

Levitzki, A. 1988. From epinephrine to cyclic AMP. Science 241: 800-806.

Lindsley, D.L. and G.G. Zimm. 1992. The genome of Drosophila melanogaster. Academic Press, New York.

Livingston, B.T. and F. H. Wilt. 1992. Phorbol esters alter cell fate during development of sea urchin embryos. J. Cell Biol. 119: 1641-1648.

Livingstone, M.S., P.P. Sziber, and W.G. Quinn. 1984. Loss of calcium/calmodulin responsiveness in adenylate cyclase of rutabaga, a Drosophila learning mutant. Cell 37: 205-215.

Mahowald, A.P. 1971. The formation of ring canals by cell furrows in Drosophila. Z. Zellforsch. 118: 162-167.

Mahowald, A.P. and M.P. Kambysellis. 1980. Oogenesis. In The genetics and biology of Drosophila (ed. M. Ashburner and T.R.F. Wright), pp. 141-224. Academic Press, New York.

Maniatis, T., R.C. Hardison, E. Lacy, J. Lauer, C. O'Connell, D. Quon, G.K. Sim, and A. Efstradiatis. 1978. The isolation of structural genes from libraries of eukaryotic DNA. Cell 15: 687-701.

Mismer, D. and G.M. Rubin. 1987. Analysis of the promoter of the ninaE opsin gene in Drosophila melanogaster. Genetics 116: $565-578$.

Morata, G. and P. Ripoll. 1975. Minutes, mutants of Drosophila autonomously affecting cell division rate. Dev. Biol. 42: 211-221.

Nakamura, T. and G.H. Gold. 1987. A cyclic nucleotide-gated conductance in olfactory receptor cilia. Nature 325: 442444.

Norris, J.L. and J.L. Manley. 1992. Selective nuclear transport of the Drosophila morphogen dorsal can be established by a signaling pathway involving the transmembrane protein Toll and protein kinase A. Genes \& Dev. 6: 1657-1667.

Otte, A.P., I.M. Kramer, and A.J. Durston. 1991. Protein kinase $\mathrm{C}$ and regulation of the local competence of Xenopus ectoderm. Science 251: 570-573.

Patel, N.H., P.M. Snow, and C.S. Goodman. 1987. Characterization and cloning of Fasciclin III: A glycoprotein expressed on a subset of neurons and axon pathways in Drosophila. Cell 48: 975-988.

Pitt, G.S., N. Milona, J. Borleis, K.C. Lin, R.R. Reed, and P.N. Devreotes. 1992. Structurally distinct and stage-specific adenylyl cyclase genes play different roles in Dictyostelium development. Cell 69: 305-317.

Rubin, G.M. and A.C. Spradling. 1982. Genetic transformation of Drosophila with transposable element vectors. Science 218: 348-353.

Sambrook, J., E.F. Fritsch, and T. Maniatis. 1989. Molecular 
cloning: A laboratory manual, 2nd ed. Cold Spring Harbor Laboratory Press, Cold Spring Harbor, New York.

Schupbach, T. and E. Wieschaus. 1989. Female sterile mutations on the second chromosome of Drosophila melanogaster-I. Maternal effect mutations. Genetics 121: 101117.

1991. Female sterile mutations on the second chromosome of Drosophila melanogaster-II. Mutations blocking oogenesis or altering egg morphology. Genetics 129: 11191136.

Simon, M.A., D.D.L. Bowtell, G.S. Dodson, T.R. Laverty, and G.M. Rubin. 1991. Rasl and a putative guanine nucleotide exchange factor perform crucial steps in signaling by the sevenless protein tyrosine kinase. Cell 67: 701-716.

Simon, M.-N., D. Driscoll, R. Mutzel, D. Part, J. Williams, and $M$. Veron. 1989. Overproduction of the regulatory subunit of the cAMP-dependent protein kinase blocks the differentiation of Dictyostelium discoideum. EMBO I. 8: 2039-2043.

Simon, M.-N., O. Pelegrini, M. Veron, and R.R. Kay. 1992. Mutation of protein kinase A causes heterochronic development of Dictyostelium. Nature 356: 171-172.

Sternberg, P.W. and H.R. Horvitz. 1991. Signal transduction during C. elegans vulval induction. Trends Gene. 7: 366371.

Studier, F.W. and B.A. Moffatt. 1985. Use of bacteriophage T7 RNA polymerase to direct selective high-level expression of cloned genes. I. Mol. Biol. 189: 113-130.

Theurkauf, W.E. and R.B. Vallee. 1982. Molecular characterization of the cAMP-dependent protein kinase bound to microtubule-associated protein 2. J. Biol. Chem. 257: 3284-3290.

Thummel, C.S., A.M. Boulet, and H.D. Lipshitz. 1988. Vectors for Drosophila P element-mediated transformation and tissue culture transfection. Gene 74: 445-456.

Toda, T., S. Cameron, P. Sass, M. Zoller, and M. Wigler. 1987. Three different genes in $S$. cerevisiae encode the catalytic subunits of the cAMP-dependent protein kinase. Cell 50: 277-287.

Toda, T., S. Cameron, P. Sass, and M. Wigler. 1988. SCH9, a gene of $S$. cerevisiae that encodes a protein distinct from, but functionally and structurally related to, cAMP-dependent protein kinase catalytic subunits. Genes \& Dev. 2: 517-527.

Tomlinson, A. and D.F. Ready. 1987. Cell fate in the Drosophila ommatidium. Dev. Biol. 123: 264-275.

Uemura, T., S. Shepherd, L. Ackerman, L.Y. Jan, and Y.N. Jan. 1989. Numb, a gene required in determination of cell fate during sensory organ determination in Drosophila embryos. Cell 58: 349-360.

van Haastert, P.J.M., P.M.W. Janssens, and C. Erneux. 1991. Sensory transduction in eukaryotes. Eur. J. Biochem. 195: 289-303.

Warn, R.M., H.O. Gutzeit, L. Smith, and A. Warn. 1985. F-Actin rings are associated with the ring canals of the Drosophila egg chamber. Exp. Cell Res. 157: 355-363.

Whitehouse-Hills, S., H.J. Bellen, and J.A. Kiger Jr. 1992. Embryonic cAMP and developmental potential in Drosophila melanogaster. Wilhelm Roux's Arch. Dev. Biol. 201: 257264. 


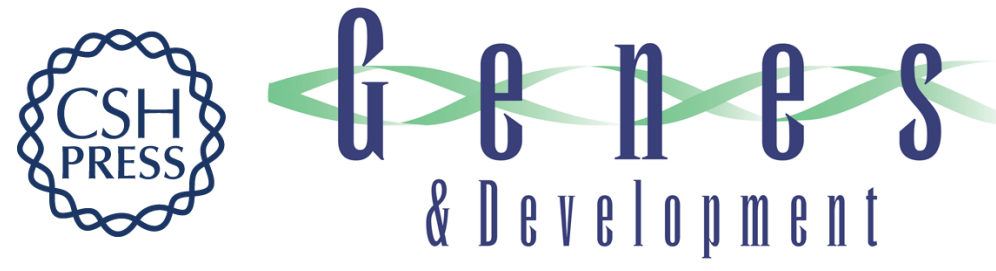

\section{Genetic investigation of cAMP-dependent protein kinase function in Drosophila development.}

M E Lane and D Kalderon

Genes Dev. 1993, 7:

Access the most recent version at doi:10.1101/gad.7.7a.1229

References This article cites 51 articles, 15 of which can be accessed free at:

http://genesdev.cshlp.org/content/7/7a/1229.full.html\#ref-list-1

License

Email Alerting

Service

Receive free email alerts when new articles cite this article - sign up in the box at the top right corner of the article or click here.

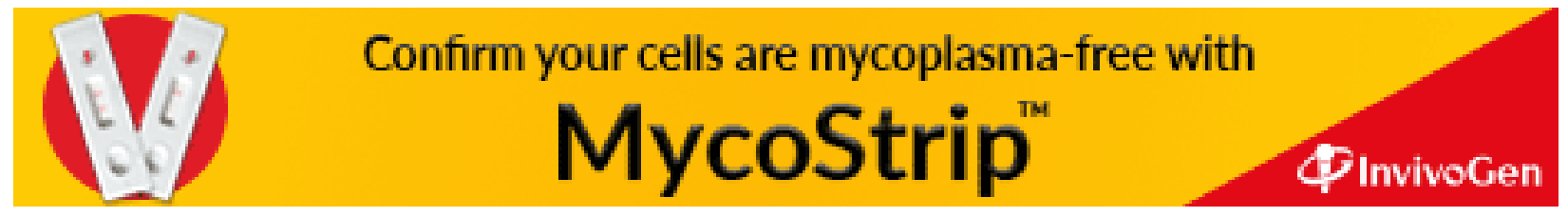

